\title{
A IMPORTÂNCIA DA EDUCAÇÃO SUPERIOR EMANCIPATÓRIA NO PROCESSO DE SUPERAÇÃO DA CRISE INTERNA DO DIREITO E DO PENSAMENTO JURÍDICO: UM CAMINHO ATRAVÉS DA METODOLOGIA JURISPRUDENCIALISTA DE ANTÓNIO CASTANHEIRA NEVES
}

\author{
LA IMPORTANCIA DE MAYOR EMANCIPATORIO EDUCACIÓN EN EL \\ PROCESO DE SUPERAR LA CRISIS DERECHO INTERNO Y PENSAMIENTO \\ JURÍDICO: UN CAMINO A TRAVÉS JURISPRUDENCIALISTA DE ANTONIO \\ NEVES CASTANHEIRA METODOLOGÍA
}

${ }^{1}$ Rômulo Geraldo Pereira

\section{RESUMO}

O presente artigo tem por objetivo principal chamar a atenção da sociedade (em especial da comunidade acadêmica) para a importância da educação superior emancipatória no processo de superação da crise interna do direito e do pensamento jurídico e demonstrar que a metodologia jurisprudencialista de António Castanheira Neves, ao propor uma abordagem critico-reflexiva do sentido e da função do direito, se apresenta como alternativa metodológica que pode contribuir para o êxito da formação superior emancipatória, pois ao assumir a compreensão do direito através de um pensamento reflexivo desenvolve a consciência crítica do jurista sobre os próprios fundamentos deste sistema social. Assim, para alcançar o objetivo proposto inicialmente será analisada a crise interna que atinge o direito e o pensamento jurídico. Na sequencia será analisada a necessidade de se reconstituir criticamente o sentido do direito. Já no terceiro capítulo será demonstrada a importância da educação superior emancipatória para a superação da crise do direito e do pensamento jurídico e como a metodologia jurisprudencialista de A. Castanheira Neves pode contribuir para o desenvolvimento de uma educação superior emancipatória.

Palavras-chave: Direito. pensamento jurídico, Crise, Superação, Educação superior emancipatória, Metodologia jurisprudencialista de antónio castanheira neves

\footnotetext{
${ }^{1}$ Mestre em Direito pela Universidade de Itaúna - UIT, Minas Gerais (Brasil). Procurador do Estado de Minas Gerais (Brasil). E-mail: romulogeraldopereira@yahoo.com.br
} 


\section{RESUMEN}

Este artículo se destina principalmente a la atención de la sociedad (especialmente la comunidad académica) a la importancia de la educación en el proceso emancipador mayor de superar la crisis interna de derecho y el pensamiento jurídico y demostrar que la metodología jurisprudencialista António Castanheira Neves, proponer un enfoque crítico y reflexivo sobre el significado y la función del derecho, se presenta como una alternativa metodológica que puede contribuir al éxito de la educación superior emancipadora porque para tomar la comprensión el derecho a través de un pensamiento reflexivo se desarrolla la conciencia crítica del jurista en los cimientos de este sistema social. Por lo tanto, para lograr el objetivo propuesto se analizará inicialmente la crisis interna de derecho y el pensamiento jurídico. La secuencia se analizará la necesidad de reconstruir críticamente el sentido de derecho. En el tercer capítulo se demostrará la importancia de la educación superior emancipadora para la superación de la crisis de derecho y el pensamiento jurídico y cómo jurisprudencialista metodología A. Castanheira Neves puede contribuir al desarrollo de la educación superior emancipatorio.

Palabras-claves: Derecho, Pensamiento jurídico, Crisis, La superación, Educación superior emancipatorio, Metodología jurisprudencialista antónio castanheira neves 


\section{INTRODUÇÃO}

É quase unanime nas atuais sociedades democráticas a ideia de que o direito é uma peça fundamental para realização dos fins comunitários. Ao reconhecer e regulamentar as regas de convivência social o direito se torna um importante instrumento de limitação dos excessos de outros sistemas sociais (político, econômico etc.). É justamente no exercício de sua função limitadora que o direito pode garantir a concretização dos ideais de liberdade e igualdade - indispensáveis à manutenção do valor humano (dignidade) no centro do projeto civilizacional de determinada comunidade.

Malgrado, os tempos hipermodernos, expressão de Lipovetsky (2004, p. 55), tem demonstrado que o instrumental discursivo do direito tem sido cooptado por outros sistemas sociais (político, econômico etc.), que se utilizam deste instrumental para viabilizar metas não compartilhadas pelos ideais que fundamentam o projeto comunitário do direito.

$\mathrm{Na}$ origem desse quadro de submissão do direito a outros sistemas sociais é possível identificar um pensamento jurídico em crise, que não mais se questiona qual o fundamento humano social do direito e admite pacificamente que este (o direito) seja relegado a simples sistema regulatório.

Diante do desvirtuamento ou esquecimento da função humano social do direito - que coloca em dúvida sua autonomia e ameaça sua própria sobrevivência - o presente estudo intenta dialogar com o jurisprudencialismo de A. Castanheira Neves, enquanto proposta de uma metodologia alternativa de realização do direito (Barroso, 2014, p. 3) para, então, demonstrar a importância da educação superior emancipatória para o processo de superação da crise interna do direito e do pensamento jurídico e, ainda, como a metodologia jurisprudencialista de A. Castanheira Neves - ao propor uma abordagem critico-reflexiva do sentido do direito - pode contribuir para implementação de uma educação superior emancipatória.

Para consecução do objetivo proposto, inicialmente será analisada a crise interna que atinge o direito e o pensamento jurídico.

$\mathrm{Na}$ sequencia será analisada a necessidade de se reconstituir criticamente o sentido do direito.

Já no terceiro capítulo será demonstrada a importância da educação superior 
emancipatória para a superação da crise do direito e do pensamento jurídico e como a metodologia jurisprudencialista de A. Castanheira Neves pode contribuir para o desenvolvimento de uma educação superior emancipatória.

Em linhas finais deste item é importante salientar que a metodologia utilizada na presente pesquisa apoiou-se nos métodos monográfico (quanto ao procedimento) e hipotéticoindutivo (quanto à abordagem). Ainda no que tange a vertente teórico metodológico foi utilizada a linha crítico-metodológica, necessária a adequada compreensão do tema e ao cumprimento dos objetivos propostos.

\section{A CRISE INTERNA DO DIREITO E DO PENSAMENTO JURÍDICO}

A crise interna do direito e do pensamento jurídico anuncia a crise do próprio homem enquanto pessoa fundadora de um projeto civilizacional (projeto ético-comunitário) que tem por fim o reconhecimento da dignidade humana e se oferece como instrumento de realização dos ideais de liberdade e igualdade.

Em crise o homem (fundamento do projeto civilizacional instrumentalizado pela ordem jurídica), o direito não teve forças para resistir à apropriação de seu instrumental discursivo por outros sistemas sociais (econômico, político etc.), por propostas não comprometidas com seus fundamentos (liberdade / igualdade). Fundamentos ético-comunitários que asseguram ao ser humano a possibilidade de ser um fim em si mesmo, de ser o fundamento de validade de toda a ordem social e de seus variados sistemas (jurídico, econômico, político etc.).

Como se percebe o problema da crise do direito se confunde com o problema de sua autonomia frente a outros sistemas sociais e com o risco de sua apropriação (funcionalização) por sistemas (econômico, político etc.) não comprometidos com seu fundamento de validade (dignidade humana) ou com os valores que permitem que o homem seja um fim em si mesmo (COELHO, 2005, p. 245).

O direito cooptado por outros sistemas sociais deixa de realizar seu projeto civilizacional - que permite o reconhecimento da dignidade humana e se oferece como possibilidade de sua liberdade (NEVES, 1967, p. 907) - e se transforma em um sistema de normas meramente regulatório para efetivação de fins políticos, econômicos etc. Sob a mesma ótica, 
[...] tal diagnóstico captura assim as diferentes funcionalizações do discurso jurídico em curso no presente, dentre as quais se destacam a funcionalização política, com a instrumentalização do direito em favor de uma intenção meramente regulatória, no contexto da transformação do Estado e da sua eficiência na efetivação de fins politicamente estabelecidos (quaisquer que sejam eles) e a funcionalização econômica, com a instrumentalização do direito e do "Estado para o desenvolvimento e a satisfação econômica-social". (COELHO, 2005, p. 246).

Realmente o direito e o pensamento jurídico não poderiam passar imunes à crise moral e cultural que permeia a sociedade "moderna" (NEVES, 2010, p. 27). O desvirtuamento dos sistemas tradicionais de valores, deixando de orientar criticamente o projeto jurídico civilizacional, permitiu que o direito se transformasse em uma ordem objetiva que passou simplesmente a ser um instrumento de garantia de uma abstrata segurança, segurança em um sistema que tem como proposta manter inalterado o sistema de forças dentro da sociedade. No mesmo sentido,

[...] a heteronomia formalmente objectiva do jurídico tradicional, com o dogmatismo hipostasiante que lhe vai associado, quando não exprima apenas a segurança - de uma segurança que os factos mostravam favorável ao sector socialmente satisfeito - sempre traria consigo, ponto mais grave ainda, o mecanismo de uma Selbstentfremdng em que o homem assistiria ao sacrifício da sua autenticidade e da sua verdade moral, em nome embora de uma objectividade normativa que não seja dele, tal como funcionava, senão a sua negação [...]. (NEVES, 2010, p. 28).

A crise do direito é justamente resultado da sua submissão a outros sistemas sociais, eis que esta permite a submissão do próprio homem a qualquer outro fim que não seja ele mesmo, e assim a negação da ideia de pessoa (COELHO, 2005, p. 26).

O pensamento jurídico, não se lançando contra a submissão do direito a outros sistemas sociais deixou de ser um "esforço de validade a exigir uma fundamentação crítica e desligou-se da eticidade humana - em que unicamente tem autonomia e sentido" (NEVES, 2010, p. 29). O pensamento jurídico deixou de se preocupar com a razão de existir do direito, com seu fundamento de validade (indiferença axiológico-normativa), e passou a se preocupar com a validação de seu sistema normativo. No mesmo sentido,

Desse modo de fez o direito acessível a uma consideração puramente "científica" - ele seria agora um simples objecto para uma intenção teorética, a realizar mediante uma estrita apreensão e determinação intelectual. É, pois, bem exacto que o positivismo jurídico permitiu fazer do pensamento jurídico uma "ciência" - a "ciência do direito". Mas do que sempre se não dá bem conta é das consequências e do verdadeiro sentido das consequências que esta nova intenção implicou para aquele pensamento. Introduzindo nele a ideia de ciência - a ideia de ciência positivista, estrutura tão só empírico- intelectual - daí resultou que a intenção teorética se viesse a substituir à intenção normativa. $\mathrm{O}$ pensamento jurídico deixou de se preocupar com a validade e a intencionalidade 
normativas do direito - momentos essências do jurídico - para curar apenas da validade e intencionalidade cognitivas de um pensamento sobre o direito: na consideração crítica, o primeiro plano deixava de ser ocupado pelo direito - o direito era apenas o dado-objecto -, e passava a ser ocupado pelo conhecimento dele. (NEVES,

2010, p. 30).

A indiferença axiológico-normativa, sustentada em nome da neutralidade e objetividade científicas, impediu o direito de assumir ou defender sua autonomia frente a outros sistemas sociais e, dessa forma, viabilizar a realização do direito enquanto sistema garantidor dos valores norteadores do projeto comunitário. O pensamento jurídico, entendendo o direito como um objeto e não como uma tarefa a ser realizada histórico-concretamente passou a absorver acriticamente tudo aquilo que lhe era apresentado como direito. No mesmo sentido salienta A. Castanheira Neves,

[...] o pensamento jurídico, a "ciência do direito", não se reconhecia a assumir em autonomia crítica a constituição-realização do direito, pois que entendendo-o apenas como objeto, mero dado, e portanto algo que lhe era transcendente com a mesma irredutibilidade dos fatos, não só estava pronto a aceitar um qualquer direito, qualquer que fosse o seu conteúdo e mérito normativo, desde que lhe fosse posto, como teria ainda de aguardar que lhe fosse dado, para só então, em atitude meramente objetiva, o apreender lógico-intelectualmente. $\mathrm{O}$ pensamento jurídico estava assim pronto a ser sancionador e colaborador de possíveis despotismos - e veio a sê-lo efetivamente. (NEVES, 2010, p. 30).

Esta, pois, a crise interna do direito - sua total e acrítica submissão a sistemas sociais que não compartilham de seus valores ou que não retiram validade do mesmo fundamento axiológico, qual seja, o ser humano como fim em si mesmo.

Contribuindo para o agravamento da crise interna do direito um pensamento jurídico reproduzido de forma acrítica, que não mais se pergunta sobre o fundamento e a validade deste sistema social.

A reprodução acrítica do pensamento jurídico retira da comunidade a capacidade de reflexão sobre o papel que o direito tem a cumprir e o deixa, o direito, susceptível de ser cooptado por outros sistemas sociais, que facilmente poderão se valer de seu instrumental discursivo para realização de quaisquer outras finalidades.

Não por outro motivo o jurisprudencialismo de A. Castanheira neves adverte que a funcionalização do direito retira deste sistema social sua essência (o direito funcionalizado deixa de ser direito) e, por consequência, retira do ser humano a possibilidade de viver como pessoa em comunidade. Cita-se no mesmo sentido, 
[...] torna-se claro que o direito, tornado instrumento para realização de quaisquer outras metas, funcionalizado quer política quer economicamente, deixa de ser direito, e deixam os homens portanto de viver como pessoas [...]. (COELHO, 2005, p. 246).

A advertência da metodologia jurisprudencialista de A. Castanheira Neves sobre a ameaça que ronda o direito e o próprio homem deve servir de combustível para impulsionar o jurista a lutar pela reconstituição crítica do sentido do direito e isto só será possível se este, em cada decisão concreta, não se esquecer de si mesmo enquanto jurista e de cada homem enquanto pessoa, pois "a decisão do jurista sobre o direito (e na verdade é cada homem um jurista enquanto vive o direito, enquanto titular do pensamento jurídico) é a decisão sobre o homem, e isto está ainda, agora, como sempre, por decidir." (COELHO, 2005, p. 247).

A reconstituição crítica do sentido do direito (único caminho para superação de sua crise interna) só será possível se o jurista deixar de ser um mero perito da técnica jurídica e passar a ser um "vivo e vigilante intérprete dos tempos, que tanto melhor sabe cumprir sua função quanto melhor alcance sentir a exigência humana da história e traduzi-la em fórmulas apropriadas de ordenada convivência", nas palavras de A. Castanheira Neves. (NEVES, 2010, p. 44).

Mas é preciso lembrar que o jurista não conseguirá cumprir sua missão no processo de reconstituição crítica do sentido do direito se não se impor institucionalmente. Para tanto, necessitará da ajuda das "instituições de juridicidade" (como são denominas por A. Castanheira Neves), quais sejam, a função judicial e as Faculdades de Direito, "com a intencionalidade axiológica e crítica que deve ser, incondicionalmente, a sua". (NEVES, 2010, p. 46). Cita-se nesse sentido ilustrativo trecho da obra do professor A. Castanheira Neve, in verbis:

Eis aqui, creio eu, as duas instituições de que depende vir ou não o direito a afirmar-se no nosso mundo humano, através da mediação indispensável do jurista: a função judicial e a Universidade. Mas para isso, evidentemente, decisivas que ambas não queiram ser apenas ancillae imperii, e sim a consciência ética da comunidade - com a independência, a responsabilidade, a coragem e o risco que os compromissos vitais sempre implicam. (NEVES, 2010, p.. 46). 


\section{A NECESSIDADE DE SE RECONSTITUIR CRITICAMENTE O SENTIDO DO DIREITO}

Como visto no item anterior, a indiferença axiológico-normativa (desenvolvimento acrítico do pensamento jurídico), sustentada em nome da neutralidade e objetividade científicas, impediu o direito de assumir ou defender sua autonomia frente a outros sistemas sociais (político, econômico etc.) o que, por consequência, possibilitou a apropriação de seu instrumental discursivo por propostas não comprometidas com seu fundamento ético-comunitário (dignidade humana).

A apropriação do instrumental discursivo do direito por sistemas sociais (econômico, político etc.) não comprometidos com o projeto ético-comunitário estruturado por este - que tem a dignidade da pessoa humana como o seu principal fundamento de validade - transformou o direito em um sistema de normas meramente regulatório, preocupado, prioritariamente, com a efetivação de fins políticos, econômicos etc.

Essa a séria e grave crise que acomete o direito e o pensamento jurídico, que ameaça sua existência e retira do ser humano a possibilidade de realizar seu projeto civilizacional de viver em uma comunidade ética. No mesmo sentido, cita-se: "[...] torna-se claro que o direito, tornado instrumento para realização de quaisquer outras metas, funcionalizado quer política quer economicamente, deixa de ser direito, e deixam os homens, portanto, de viver como pessoas". (COELHO, 2005, p. 246).

Também salientando a gravidade da crise que assombra o direito e o pensamento jurídico, cita-se:

É esta, pois, a crise interna do direito, aquela que não apenas no futuro, mas já hoje o atinge. Crise das mais graves que o jurídico alguma vez sofreu: o direito a correr o risco de ser negado como direito; o pensamento jurídico a recusar o direito, enquanto tal, como a sua intenção problemática, e a diluir-se por isso em intencionalidades anormativas em que apaga a sua autonomia, e, portanto, a si mesmo anula. (NEVES, 2010, p. 31).

Fica evidente que a crise do direito surge quando o pensamento jurídico esquece que o direito deve ser construído (realizado) histórico-concretamente; quando se esquece do valor que fundamenta (dignidade humana) seu projeto civilizacional e passa, de forma acrítica, a se preocupar com a validação de seu conhecimento "científico". No mesmo sentido, 
Ora, em face desta situação tão grave, como vemos o pensamento jurídico reagir? Desse modo: insistindo numa atitude essencialmente epistemológica, toda a sua preocupação é fundamentar a possibilidade de uma auntónoma ciência do direito. O jurista, como que pressentido o espectro do desemprego, parece só preocupado em garantir-se um domínio próprio de ocupação, e ocupação que não o diminuísse aos olhos do cientificismo do século, ao qual é seu desejo queimar incenso. [...] Mas temos para nós que o caminho está errado. O descompromisso teórico ("científico") se, por um lado, não evita a degradação do direito - só a potencia -, também por outro lado, não assegura ao jurista a desejada irresponsabilidade - antes, será ele inevitavelmente arguido de omissão (digamos abdicação) da atitude que o seu próprio estatuto social e moral the prescreve: dirigir o direito ao serviço do homem. (NEVES, 2010, p. 32).

Indicando um caminho no sentido da superação da profunda crise que atinge o direito e o pensamento jurídico a metodologia jurisprudencialista de A. Castanheira Neves adverte que é preciso reconstituir criticamente o sentido do direito.

Porém, para que seja possível se alcançar essa meta A. Castanheira Neves salienta que o jurista precisa compreender que o direito não é um dado, mas uma tarefa que o chama a um esforço e a uma responsabilidade. (Neves, 2010, p. 32).

A reconstituição crítica do sentido do direito passa necessariamente por três questões dirigidas tanto ao direito como ao jurista. A primeira volta-se para o fundamento de validade do direito enquanto tal; a segunda indaga sobre a função humano-social do jurídico; a terceira e última se encarrega de analisar a forma como o jurista poderá se desincumbir da tarefa que a construção do direito impõe. (NEVES, 2010, p. 10).

A busca pelo fundamento de validade do direito remete a principal questão que deve ser enfrentada pelo pensamento jurídico, pois esta é a indagação que está na base da compreensão de qualquer problema jurídico. Afinal, para que o jurista possa apresentar uma solução adequada a determinada questão jurídica o mesmo precisa compreender o fundamento de validade que legitima o direito enquanto sistema social.

A metodologia jurisprudencialista de A. Castanheira Neves, entendendo que apenas o homem pode dar sentido ao mundo, defende que o fundamento de validade do direito não pode estar em conceitos ou valores pré-determinados, ao contrário, deve ser extraído da intenção éticocomunitária que une o homem em uma comunidade de pessoas. Nesse sentido cita-se,

Ora a intenção ético-comunitária das pessoas, intenção que elas assumem numa ideia totalizante - essa intenção outra coisa não é que a Ideia de Direito. Neste sentido é o direito intenção e dimensão da própria pessoal moral, pois é ele aquela intencionalidade que a pessoa, situada axiologicamente na realidade da convivência ética, assume ao transcender-se numa intenção comunitária, e enquanto é essa intenção comunitária condição real da existência da pessoa como pessoa. (NEVES, 2010, p. 39). 
Assim, se o fundamento de validade do direito está na intencionalidade comunitária, resta claro que este fundamento não pode estar em conceitos ou valores pré-determinados, ao contrário, nasce do projeto civilizacional que vai sendo construído histórico-concretamente pela comunidade. Nesse sentido, pode-se afirmar que "a ideia de direito é a intenção axiológica da realização comunitária." (NEVES, 2010, p. 40).

Salientado que o fundamento de validade do direito deve ser buscado na intenção axiológica que envolve o projeto civilizacional que une o homem a uma comunidade de pessoas, é preciso verificar qual a função humano-social do direito, sem a qual o mesmo perderia sua autonomia e seria relegado a mero sistema regulatório.

Identificando-se o direito com o projeto axiológico da vida comunitária que permite ao homem viver enquanto pessoa (dotada de dignidade) fica fácil perceber que a função humanosocial do direito consiste justamente em viabilizar as relações humanas na convivência éticocomunitária. Nesse sentido, o direito é um instrumento de afirmação da dignidade e liberdade do homem. (NEVES, 2010, p. 17).

Após analisar o fundamento de validade e a função humano-social do direito, verificando que este propõe um esforço válido e justificável, o jurista precisa indagar a si mesmo como poderá se desincumbir da tarefa que este (o direito) impõe para sua efetiva realização comunitária. Esta a questão metodológica que indaga pela "forma" ou pelo "como" o direito poderá ser realizado histórico-concretamente.

Discorrendo sobre o problema metodológico da realização do direito a metodologia jurisprudencialista de A. Castanheira Neves chama a atenção para três pontos que não podem ser desconsiderados pelos juristas. Nesse sentido salienta que primeiramente o jurista jamais poderá se esquecer de que sendo o direito um instrumento de realização do projeto civilizacional de determinada comunidade ética o mesmo não poderá ser confundido com a lei. "O direito como prática social complexa precisa decidir casos, justificar decisões, produzir normas. Algo muito distante de um simples conjunto de princípios e de regras [...]." (BARROSO, 2014, p. 7). Cita-se no mesmo sentido,

[...] primeiro para nos advertirmos de que, sendo o direito o cumprimento da sua ideia num contexto-comunitário, será ele sempre mais e coisa distinta da lei. Nem mesmo se confundirá com o sistema de direito positivo, se com este se pensar numa totalidade racional fechada e não uma intenção de totalização sempre aberta a um específico dinamismo e enriquecimento históricos. (NEVES, 2010, p. 46).

Revista de Pesquisa e Educação Jurídica | e-ISSN: 2525-9636 | Minas Gerais | v. 1 | n. 2 | p. 137 - 153 | Jul/Dez. 2015. 
Depois, o jurista terá que enfrentar o problema da aplicação do direito. Nesse passo terá que ter em mente que o direito, entendido como instrumento de realização comunitária, impõe que "o prius metódico deixa de localizar-se na norma (formulação lógico-significativa), para se localizar no caso concreto da vida sobre cuja validade jurídica haverá de pronunciar-se" (NEVES, 2010, p. 47). Assim, os fatos relevantes para o deslinde da causa deixam de ser apenas aqueles previamente selecionados pela norma positivada e passam a ser verificados no próprio caso a ser analisado.

Por fim, o jurista, na tarefa de realização do direito, terá que assumi-lo como uma "intenção fundamentante de caráter axiológico", na expressão de A. Castanheira Neves. O jurista, o pensamento jurídico, precisa se manter fiel a sua intenção normativa e assumir com autonomia o próprio problema normativo do direito. (NEVES, 2010, p. 49).

\section{A IMPORTÂNCIA DA EDUCAÇÃO SUPERIOR EMANCIPATÓRIA NO PROCESSO DE RECONSTITUIÇÃO CRITICA DO SENTIDO DO DIREITO E A ALTERNATIVA JURISPRUDENCIALISTA DE A. CASTANHEIRA NEVES}

Analisada a crise interna do direito e do pensamento jurídico e, ainda, visto que tão grave crise somente poderá ser superada através da reconstituição crítica do sentido do direito, passa-se a analisar a importância da educação superior emancipatória para o processo de reconstituição critica do sentido do direito e como a metodologia jurisprudencialista de A. Castanheira Neves pode contribuir para o êxito deste processo.

Como adverte a metodologia jurisprudencialista de A. Castanheira Neves o direito precisa de um mediador que assuma sua intenção e possibilite sua realização históricoconcretamente, pois o direito é uma tarefa que deve ser realizada diariamente. Cita-se nesse sentido,

[...] a verdadeira intenção do direito é, negativamente, a de impedir o homem do esquecimento de si próprio, e positivamente, a de o afirmar no seu ser e, assim, no seu valor.

Só que esta intenção, para poder ser cumprida, envolve exigências específicas. Pois essa intenção (o direito) é aquela que vimos ser - uma tarefa problemática a realizar historicamente em acto - não pode ela prescindir de um mediador que, assumindo aquela intenção, haja de ser o sujeito deste acto. É certo que o sujeito da juridicidade é a própria comunidade social enquanto comunidade ética, mas esta não será susceptível de realizarse como tal se o seu próprio projecto axiológico não lhe for explicitado e fundamentado criticamente. Se a comunidade subsiste na sua existência histórica, o projecto e a 
totalização axiológicos serão sempre uma intencionalidade criticamente espiritual. Ora esta é justamente - cremo-lo bem - a verdadeira função do jurista: a de assumir criticamente a ideia de direito e de realizar histórico-concretamente, na explicitação constituinte do próprio direito. (NEVES, 2010, p. 43).

Sendo, pois, função do jurista explicitar e fundamentar criticamente o projeto civilizacional que subsiste por trás da ideia de direito (projeto comunitário do direito), resta evidente que este (o jurista) precisa ter autonomia critica para desempenhar esta tarefa. Assim, o jurista precisa se apoiar e ser esclarecido por uma instituição crítica (Faculdade de Direito), daí a importância da formação superior emancipatória. Cita-se nesse sentido,

[...] não poderá cumprir validamente a sua missão se não se apoiar e não for esclarecida por uma instituição crítica - aquela crítica que explicite e fundamente o próprio projeto comunitário do direito. E já vimos que esta é a função do jurista em geral. Só que temos por certo que o jurista a não poderá cumprir se não lograr também ele impor-se institucionalmente, já que o jus respondendi pessoal não é mais do nosso tempo - penso nas instituições de juridicidade que são as universitárias Faculdades de Direito, com a intencionalidade axiológica e crítica que deve ser, incondicionalmente, a sua. (NEVES, 2010, p. 46).

A formação superior emancipatória permitirá que o jurista atue com a necessária autonomia crítica, indispensável para que este, a cada dia, promova a reconstituição do sentido do direito e o adeque às sempre novas exigências sociais. No mesmo sentido,

Por isso, o comprometimento com as formas de aprendizado jurídico contribui para a formação de indivíduos capazes de realizar o questionamento propulsor do contínuo processo de construção e desconstrução do saber orientado para a integração social. (BARROSO; CUNHA, 2014, p. 7).

O jurista moderno precisa ter autonomia critica até mesmo para visualizar a possibilidade do não direito. É certo que o direito representa o projeto civilizacional que traduz o reconhecimento da dignidade humana e possibilita a realização dos ideais de liberdade e igualdade. Malgrado, o jurista precisa compreender que "o direito é uma possibilidade axiológica, e não uma necessidade antropológica" (COELHO, 2005, p. 228). O direito é um projeto civilizacional (projeto ético-comunitário) instituído pelo homem, não um dado que sempre existiu ou deve sempre existir. Assim, cabe ao jurista, a cada decisão jurídica concreta, reconstituir e validar a ideia de direito ou, não fazê-lo, pois o direito não é um dom, é uma tarefa, um esforço comunitário. (COELHO, 2005, p. 229). 
Daí a importância da educação superior emancipatória, pois através da contribuição desta o jurista poderá adquirir a autonomia crítica indispensável à realização de sua importante missão (função) social, qual seja, fundamentar criticamente o projeto civilizacional que subsiste por trás da ideia de direito.

Nesse contexto, fica fácil perceber que a crise que atinge o direito e o pensamento jurídico indica que a formação jurídica superior não tem conseguido formar de forma adequada o jurista de nosso tempo.

A reprodução acrítica de uma quantidade infindável de conteúdos jurídicos (ministrados nas e pelas Faculdades de Direito) acaba resultando na formação de juristas incapazes de extrair criticamente o sentido social (ético-comunitário) de determinada norma ou instituto jurídico função primordial do jurista.

Ante este quadro de crise eis que surge uma esperança: a metodologia jurisprudencialista de A. Castanheira Neves. Esta, propondo uma abordagem critico-reflexiva do sentido e da função do direito, se apresenta como alternativa metodológica que pode contribuir para formação superior emancipatória.

A abordagem jurisprudencialista assume a compreensão do direito através de um pensamento reflexivo do próprio direito enquanto pensamento jurídico. Assim, enquanto metodologia, o pensamento jurídico desenvolve a consciência crítica sobre seus próprios fundamentos.

O método de trabalho jurisprudencialista (crítico-reflexivo) não admite a reprodução acrítica de conteúdos jurídicos, pois todo conteúdo jurídico deve, necessariamente, ser analisado à luz do projeto civilizacional instituído pela comunidade de pessoas (comunidade ética). Nesse sentido, a metodologia jurisprudencialista conduzirá o jurista a uma atitude crítico-reflexiva que terá no projeto ético-comunitário seu horizonte de fundamentação. (COELHO, 2005, p. 222). No mesmo sentido,

Enquanto metodologia, o pensamento jurídico recobra a consciência crítica sobre seus próprios fundamentos, na auto revelação dos sentidos últimos constitutivos da juridicidade e do modo como se constituem, reavendo assim ao mesmo tempo consciência sobre seu modo próprio enquanto logos. Nesse sentido, a metodologia prepara e possibilita a filosofia do direito, como reflexão situada historicamente e fundada na historicidade mesma de seu campo de reflexão. (COELHO, 2005, p. 222). 
Assim, ao possibilitar que o pensamento jurídico recobre sua consciência crítica sobre o fundamento de validade do direito, a metodologia jurisprudencialista de A. Castanheira Neves se apresenta como uma alternativa capaz de contribuir para formação superior emancipatória indispensável ao processo de reconstituição crítica do sentido do direito e, por consequência, à superação da crise interna que atinge o direito e o pensamento jurídico.

\section{CONCLUSÃO}

Como salientado ao longo do presente estudo o problema da crise do direito se confunde com o problema de sua autonomia frente a outros sistemas sociais e com o risco de sua apropriação (funcionalização) por sistemas (econômico, político etc.) não comprometidos com seu fundamento de validade (dignidade humana) ou com os valores que este incorpora para assegurar que o homem seja o fundamento de validade de toda a ordem social e de seus variados sistemas (jurídico, econômico, político etc.).

O desvirtuamento dos sistemas tradicionais de valores, deixando de orientar criticamente o projeto jurídico civilizacional, permitiu que o direito se transformasse em uma ordem objetiva que passou simplesmente a ser um instrumento de garantia de uma abstrata segurança, segurança em um sistema que tem como proposta manter inalterado o sistema de forças dentro da sociedade.

Malgrado, o jurista não pode aceitar de forma pacífica que o direito seja cooptado por outros sistemas sociais que o utilizam como mero instrumento regulatório para efetivação de fins políticos, econômicos etc.

A crise interna do direito e do pensamento jurídico impõe ao jurista a importante e complexa missão promover a reconstituição critica do sentido do direito, pois a este cabe a função de explicitar e fundamentar criticamente o projeto civilizacional que subsiste por trás da ideia de direito (projeto comunitário do direito).

Porém, para desempenhar essa importante tarefa o jurista não pode se contentar em ser um mero perito da técnica jurídica. Ao contrário o jurista precisa se manter fiel ao projeto ético comunitário do direito e assumir essa intenção em cada caso concreto, sobre cuja validade jurídica for chamado a se pronunciar. É o que adverte A. Castanheira Neves quando defende que 
o jurista deve ser um vivo e vigilante intérprete dos tempos. Cita-se, nesse sentido, o esclarecedor trecho de sua obra, in verbis:

[...] não poderá ser o jurista apenas o perito da técnica jurídica, mas um vivo e vigilante intérprete dos tempos, que tanto melhor sabe cumprir sua missão quanto melhor sentir a exigência humana da história e traduzi-la em fórmulas apropriadas de ordenada convivência. (NEVES, 2010, p. 44).

A advertência de A. Castanheira Neves deve servir de combustível para impulsionar o jurista a lutar pela reconstituição crítica do sentido do direito e isto só será possível se este, em cada decisão concreta, não se esquecer de si mesmo enquanto jurista e de cada homem enquanto pessoa.

Fica evidente que para enfrentar a crise interna do direito e do pensamento jurídico, o jurista não pode se contentar em desempenhar apenas sua função técnico-científica. Ao contrário, deve, também, desempenhar a função de intérprete da ideia de direito na comunidade e para a comunidade.

Assumindo o jurista a função de intérprete da ideia de direito (função axiológica) dentro da comunidade - função que implica, inevitavelmente, uma séria responsabilidade, eis que impõe ao jurista o dever de dizer não às situações de não direito - deve ele ter a necessária autonomia para assumir e defender a ideia de direito inscrita o projeto civilizacional de seu tempo, sem se esquecer de que o direito é uma tarefa que deve ser realizada diariamente (histórico- concretamente).

Nesse contex to é fácil intuir que o jurista estará cada vez mais preparado para desempenhar sua função axiológica se contar com uma educação superior emancipatória, que o capacite a analisar de forma independente, autônoma e crítica tudo aquilo que é apresentado à comunidade como sendo direito para, então, "sentir a exigência humana da história e traduzi-la em fórmulas apropriadas de ordenada convivência" (NEVES, 2010, p. 44).

Eis a importância da educação superior emancipatória no processo de superação da crise que atinge o direito e o pensamento jurídico: formar juristas capacitados a desempenhar a função de intérprete da ideia de direito na comunidade e, por consequência, habilitados a assumirem com autonomia crítica o problema normativo do direito.

Como dito, jurista moderno precisa compreender que o direito é um projeto civilizacional (projeto ético-comunitário) instituído pelo homem, não um dado que sempre existiu ou deve sempre existir. 
Cabe ao jurista, a cada decisão jurídica concreta, reconstituir e validar a ideia de direito ou, não fazê-lo, pois o direito não é um dom, um dado ou um achado. O direito é uma tarefa a ser realizada diariamente (histórico-concretamente) que exige do jurista um olhar crítico, forjado no seio de uma educação superior emancipatória - que o possibilite analisar criticamente os problemas sociais e, acima de tudo, o projeto ético comunitário de sua comunidade.

Nesse contexto, propondo uma abordagem critico-reflexiva do sentido e da função do direito, a metodologia jurisprudencialista de A. Castanheira Neves se apresenta como alternativa metodológica que pode contribuir para formação superior emancipatória, pois ao assumir a compreensão do direito através de um pensamento reflexivo desenvolve a consciência crítica do jurista sobre os próprios fundamentos do direito. 


\section{REFERÊNCIAS}

BARROSO, L. A. Para além do positivismo jurídico... A metodologia jurisprudencialista de A. Castanheira Neves: reconstruindo o sentido do direito na contemporaneidade. Artigo apresentado durante as aulas do primeiro semestre (ano de 2014) do Mestrado em Direito da Universidade de Itaúna - MG.

BARROSO, L. A; CUNHA, Mirlir. A crítica como pressuposto de uma formação superior emancipatória: os limites da educação jurídica no Brasil diante do desenvolvimento do ensino à distancia. Disponível em: http://www.ismat.pt/images/PDF/jurismat4_opt.pdf. Acesso em 10 de março de 2015.

CASTANHEIRA NEVES, António. O papel do jurista no nosso tempo. In: NEVES, A. Castanheira (Org.). Digesta: escritos acerca do direito, do pensamento jurídico, da sua metodologia e outros. Coimbra: Coimbra Editora, 2010, v. 1.

Questão-de-Fato - Questão-de-Direito - ou o Problema Metodológico da Juridicidade (Ensaio de uma reposição crítica). Coimbra: Livraria Almedina, 1967.

COELHO, Nuno M. M. S. O princípio ontológico da historicidade radical e o problema da autonomia do direito: ensaio de aproximação filosófica do jurisprudencialismo. Revista da Faculdade de Direito da UFMG. n. 47, 2005. Disponível em: http://www.direito.ufmg.br/revista/index.php/revista/article/view/228. Acesso em 05 de junho de 2015.

LIPOVETSKY, Gilles. Os tempos hipermodernos. Tradução: Mário Vilela. São Paulo: Barcarolla, 2004. 